\title{
Research on self-centering ability of tapered roll for initial flatness waves of steel strip in the continuous annealing furnace
}

\author{
Kezhi Linghu ${ }^{1} \mathrm{a}^{\star}$, , Zhengyi Jiang ${ }^{2}$, ${ }^{\mathrm{b}}$ Wei Tang ${ }_{1}^{3}{ }_{\mathrm{f}}^{\mathrm{c}}$ Meng $\mathrm{Yu}^{1},{ }^{\mathrm{d}}$ Fengqin Wang ${ }^{1}$, \\ Xueqi Huang ${ }^{1}$,
}

1Shougang Research Institute of Technology, Shougang Group, No.69 Yangzhuang Street, Shijingshan District, Beijing 100043, China

\author{
2School of Mechanical, Materials \& Mechatronic Engineering, University of Wollongong, \\ Wollongong, NSW 2522, Australia \\ 3Shougang Jingtang United Iron \& Steel Co. Ltd., Caofeidian Industrial Development Zone, \\ Tangshan 063200, China

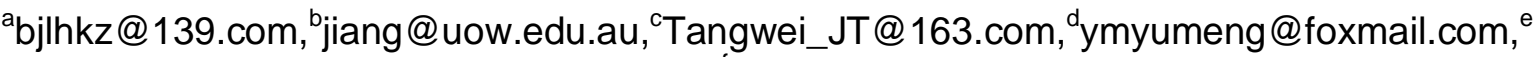 \\ wfq_sg@163.com,'hxq@shougang.com.cn
}

\begin{abstract}
Keywords: steel strip; continuous annealing furnace; initial flatness;self-centering;snaking
Abstract: The snaking of strip in the continuous annealing furnace affects both the process stability of production line significantly and the quality of final products. This paper for the first time proposed the self-centering ability of tapered hearth roll on initial flatness of strip travelling in the furnace and a FEM model that coupling the strip and furnace roll is constructed to simulate the traveling process of strip in the furnace. The self-centering ability is quite different with respect to the different initial flatness waves of strip traveling in the furnace and can be used for optimization of initial flatness of strip for stability improvement.
\end{abstract}

\section{Introduction}

Continuous annealing is often adopted in the post processing of steel strip production process $[1,2]$, which has advantages of high productivity, high output, good product quality and clean product surface etc. [3, 4].However the strip is likely to snaking during heat treatment since it travels through several hearth rolls and is prone to travel off centre [5-9]. In some cases, a strip could scratch furnace walls, leading to the strip breaking and causing remarkable economic loss. In order to solve this problem, reference [10] mainly analysed the large elongation, sliding and snaking of strip steel in the furnace area. A mathematical model on silicon steel continuous annealing has been established in reference [11] based on the working principle of the correction electro-hydraulic position servo system. Reference [12] studied the relationship between the asymmetry of cross section of strip and its snaking in furnace, and optimised the cross section's dimension of chilled rolls to reduce the snaking. In order to reduce the snaking of strip, reference [6] analysed the mechanism of correcting snaking of tapered roll with "flat" strip. It is proved that rolled strips would have flatness flaws more or less in term of middle waves or edge waves $[13,14]$.

Since there is little research on the correcting snaking ability for coupled tapered hearth roll and "non-flat" strip with initial strip flatness defects, the paper will propose a finite element (FE) model to investigate the self-centering ability of tapered roll on different initial flatness .

\section{Finite element model}

Because the thickness of strip is usually less than $2 \mathrm{~mm}$, its width is greater than $1800 \mathrm{~mm}$, and the ratio of width to thickness is greater than 900 , the theory of plate and shell is adopted to build up a finite element (FE) model[15, 16]. 


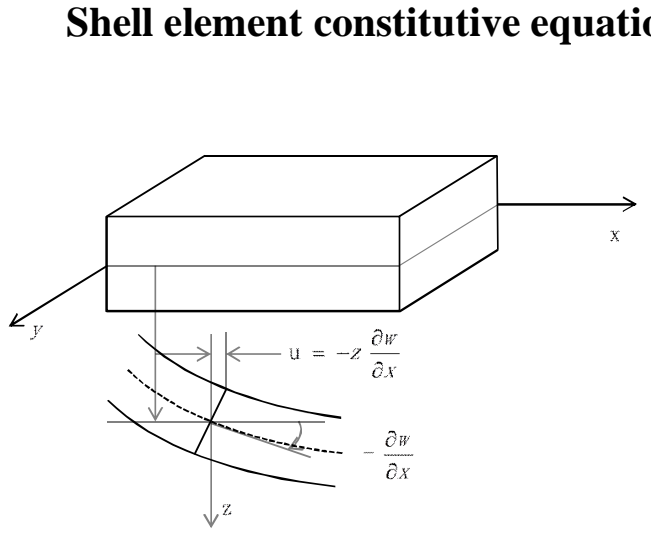

(a)

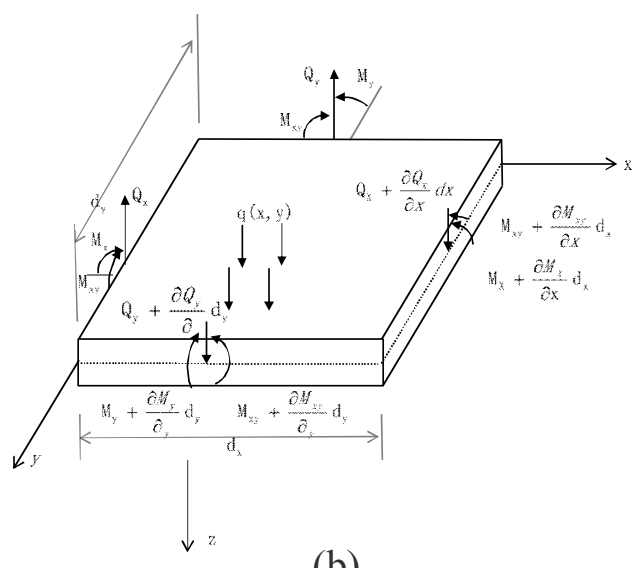

(b)

Fig.1. Schematic diagram of steel shell element: (a) bending deformation of a steel sheet, (b) integrated force diagram.

As illustrated in Fig. 1(a), assuming that a strip has plane displacements $\mu$ and $v$ in the directions of $\mathrm{X}$ and $\mathrm{Y}$, and that central plane's longitudinal displacement is $\mathrm{w}$, by neglecting lateral shear deformation, formulas of plane strain can be described as

$$
\left\{\begin{array}{l}
\varepsilon_{x x} \\
\varepsilon_{y y} \\
\gamma_{x y}
\end{array}\right\}=\left\{\begin{array}{c}
\frac{\partial w}{\partial x} \\
\frac{\partial v}{\partial y} \\
\frac{\partial_{u}}{\partial y}+\frac{\partial v}{\partial x}
\end{array}\right\}=\left\{\begin{array}{c}
-z \frac{\partial^{2} w}{\partial x^{2}} \\
-z \frac{\partial^{2} w}{\partial y^{2}} \\
-2 z \frac{\partial^{2} w}{\partial x \partial_{y}}
\end{array}\right\}=-z\left\{\begin{array}{c}
x_{x} \\
y_{y} \\
x_{x y}
\end{array}\right\}
$$

where vector $\{x\}=\left[x_{x}, x_{y}, x_{x y}\right]^{T}$ is buckling vector or generalised strain.

torsion and shear stress are the results of stress tensor, and they can be calculated as:

$$
\begin{gathered}
M_{x x}=\int_{-h / 2}^{h / 2} \sigma_{x x} z d z ; M_{y y}=\int_{-h / 2}^{h / 2} \sigma_{y y} z d z ; M_{x y}=\int_{-h / 2}^{h / 2} \tau_{x y} z d z \\
Q_{x x}=\int_{-h / 2}^{h / 2} \sigma_{x x} z d z ; \quad Q_{y y}=\int_{-h / 2}^{h / 2} \sigma_{y y} z d z
\end{gathered}
$$

To the bending of shell element, there is a relationship as follows,

$$
\begin{array}{r}
\{\sigma\}=[D]\{\varepsilon\} \\
\text { Where }[D]=\frac{E}{1-v^{2}}\left[\begin{array}{c}
1, v, 0 \\
v, 1,0 \\
0,0, \frac{(1-v)}{2}
\end{array}\right]
\end{array}
$$

Substituting equations (2) and (4) into equation (3), then the constitutive equation is obtained.

$$
\begin{array}{r}
\{\sigma\}=-z[D][\mathrm{x}\} \\
\{M\}=\frac{h^{2}}{12}[D]\{x\}
\end{array}
$$

As shown in Fig. 1(b), the equilibrium equation of shell element in $\mathrm{Z}$ direction can be obtained.

Simplifying

$$
-Q_{x} d y-Q_{y} d+\left(Q_{x}+\frac{\partial Q_{x}}{\partial x} d x\right) d y+\left(Q_{x}+\frac{\partial Q_{y}}{\partial y} d y\right) d x+q(x, y) d x d y=0
$$

$$
\frac{\partial Q_{x}}{\partial x}+\frac{\partial Q_{y}}{\partial y}+q(x, y)=0
$$

Based on the principle of torque balance in $X$ and $Y$ direction,

Substituting equations (10) into equation (9)

$$
\frac{\partial M_{x y}}{\partial x}+\frac{\partial M_{y y}}{\partial y}=Q_{y} ; \frac{\partial M_{x y}}{\partial y}+\frac{\partial M_{y y}}{\partial x}=Q_{x}
$$

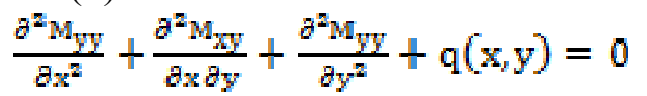

then rectangular shell element general differential equation can be expressed as

$$
\begin{aligned}
& \frac{a^{4} w}{g x^{4}}+\frac{g^{4} w}{g^{2} g^{2} y}+\frac{\partial^{4} w}{\partial y^{4}}=\frac{\mathrm{q}(x, y)}{\mathrm{D}_{\mathrm{r}}} \\
& \text { Where } \mathrm{D}_{\mathrm{r}}=\frac{\mathrm{Fh}^{3}}{12\left(1-\mathrm{v}^{2}\right)}
\end{aligned}
$$




\section{D shell element model}

Due to the big ratio of width to thickness, shell element is more suitable for FE simulation $[15,17]$. Frequent initial flatness defects, such as edge waves, double-edge waves are simulated in a $3 \mathrm{D} \mathrm{FE}$ model as shown in Fig. 2.

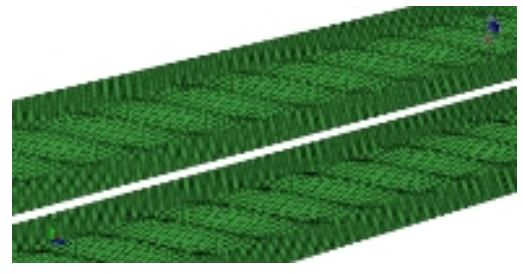

(a)

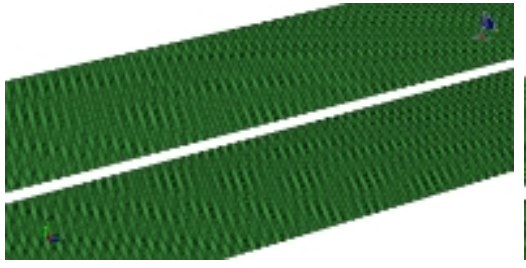

(b)

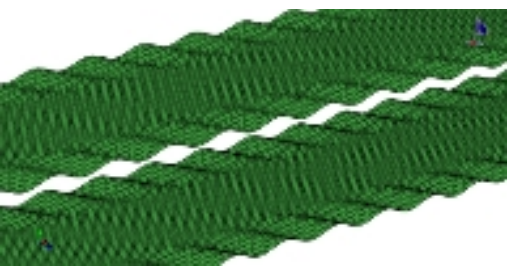

(c)

Fig. 2. FEM models of steel strip with different initial flatness defects: (a) center waves, (b) flat waves , and (c) double edge waves.

\section{Material parameters}

The material parameters in FE simulation is displayed in Table 1.

Table 1 Parameters of FEM model for steel strip and hearth roll

\begin{tabular}{lllllll}
\hline Item & Material & Elasticity Modulus & Yield Stress & Poisson ratio & Density & Remark \\
\hline Steel Strip & DC04 & $210 \mathrm{GPa}$ & $100 \mathrm{MPa}$ & 0.3 & $7800 \mathrm{Kg} / \mathrm{m} 3$ & \\
Hearth Roll & STEEL & $210 \mathrm{GPa}$ & $300 \mathrm{MPa}$ & 0.3 & $7800 \mathrm{Kg} / \mathrm{m} 3$ & \\
\hline
\end{tabular}

\section{Coupling model between strip and hearth roll}

Four parameters wave width (Ws), wave height (Hs), wave length (Ls) and initial wave position (Ps) have been used to describe to initial flatness defects as illustrated in Fig. 3.
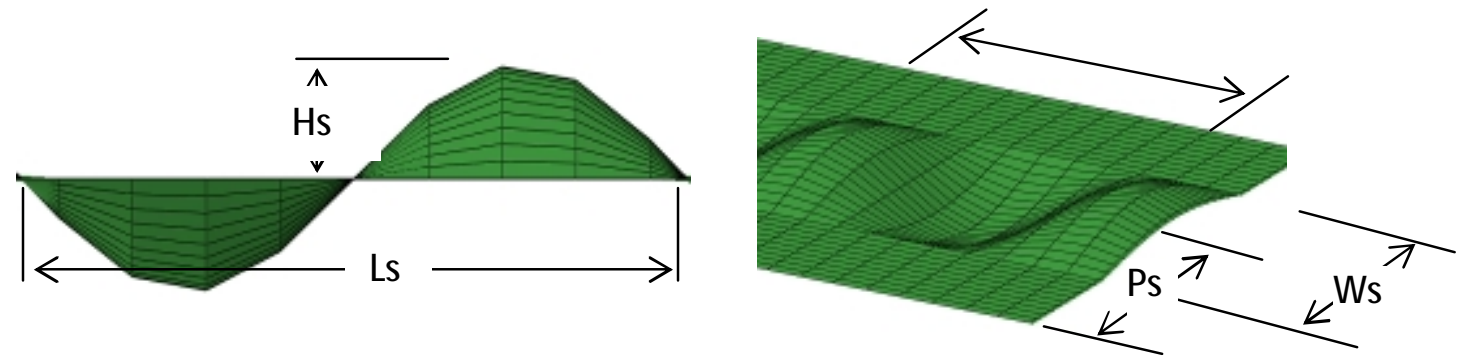

Fig. 3. Parameters used to describe initial flatness defects.

It can be seen in Fig. 4 that the strip is located in the middle of hearth roll, and the main geometrical parameters are: strip width (W) $1800 \mathrm{~mm}$, central cylinder width (W1) $700 \mathrm{~mm}$, tapered area width (W2) $900 \mathrm{~mm}$, maximum roll diameter (D1) $900 \mathrm{~mm}$ and minimum roll diameter (D2) 895mm. the "x" denotes initial off-center distance between strip and roll.

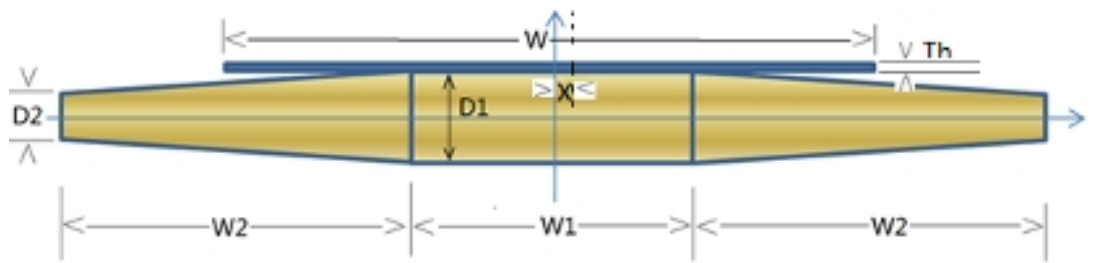

Fig. 4. Schematic diagram of coordinate system for strip-hearth roll coupling model. 
Based on shell elements and the abovementioned coordinates, the FE simulation coupling model of strip and hearth roll is established as shown in Fig. 5. In this paper, self-centering ability of tapered hearth roll is investigated by setting the initial off-centering distance of strip and calculating the movement of strip toward the center of hearth roll.
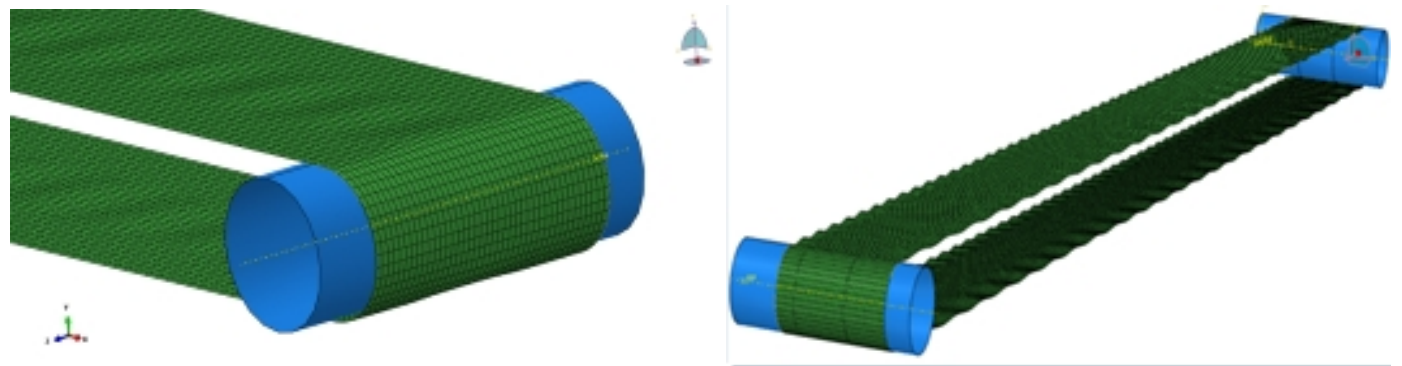

Fig. 5. FEM coupling model of strip, hearth roll and tension.

\section{Self-centering ability of tapered roll}

\section{Influence of initial waves}

Keeping the values of strip width $(\mathrm{W}=1800 \mathrm{~mm})$, thickness $(\mathrm{Th}=1 \mathrm{~mm})$, tension stress $(6 \mathrm{MPa})$ and initial off-center distance $(\mathrm{x}=15 \mathrm{~mm})$ unchanged, and setting the parameters of Center Waves, Double Edge Waves, Flat Non-Waves respectively as follows:

Center Waves: initial wave width $(\mathrm{Ws}=360 \mathrm{~mm})$, wave height $(\mathrm{Hs}=10)$, length $(\mathrm{Ls}=300 \mathrm{~mm})$, position (Ps=900mm).

Double Edge Waves: initial wave width $(\mathrm{Ws}=360 \mathrm{~mm})$, wave height $(\mathrm{Hs}=10)$, length $(\mathrm{Ls}=300 \mathrm{~mm})$, position $(\mathrm{Ps}=0 \mathrm{~mm}$ and $\mathrm{Ps}=1800)$.

Flat Non-Waves: strip is flat without any wave.

Due to initial off-center distance $(x=15 \mathrm{~mm})$ and different initial flatness mentioned above, the tapered hearth roll corrects (reduces) the off-center distance of strip in transverse direction, the change of off-center distance of strip with respect to traveling distance processed is shown in Fig. 6.

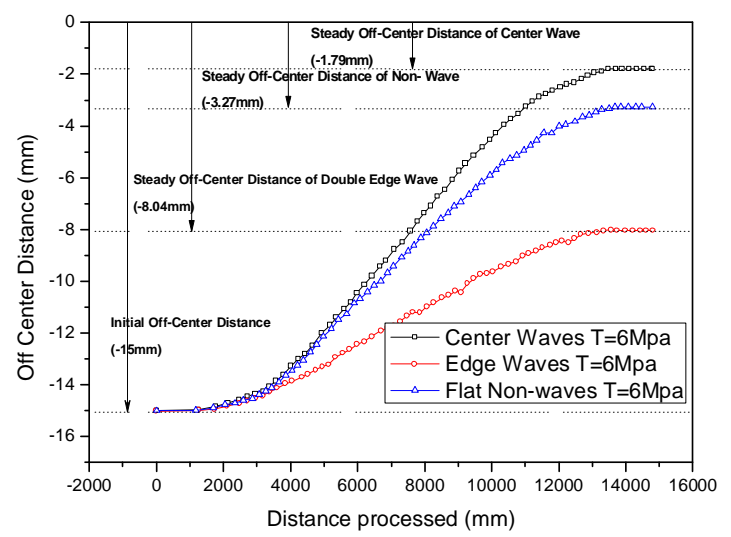

Fig. 6. The change of off-center distance of strip with different initial flatness

From the calculation results, it is obvious that the tapered hearth roll has the self-centering ability to move the strip with initial off-center distance toward the center of hearth roll. For a given tapered hearth roll, keeping the values of strip width, thickness, wave width, wave height, wave length and initial off-center distance unchanged, the self-centering ability for center waves is greater than that for flat non-waves, while the self-centering ability for double edge waves is less than that for flat non-waves.

\section{Influence of tension stress in the furnace}

Keeping the values of strip width $(\mathrm{W}=1800 \mathrm{~mm})$, thickness $(\mathrm{Th}=1 \mathrm{~mm})$, initial center wave width $(\mathrm{Ws}=360 \mathrm{~mm})$, wave height $(\mathrm{Hs}=10)$, length $(\mathrm{Ls}=300 \mathrm{~mm})$, position $(\mathrm{Ps}=900 \mathrm{~mm})$, and 
initial off-center distance $(\mathrm{x}=15 \mathrm{~mm})$ unchanged, and setting the value of tension stress $6 \mathrm{MPa}, 8$ Mpa and 4 Mpa respectively.

Due to initial off-center distance $(\mathrm{x}=15 \mathrm{~mm})$ and different initial tension stress the tapered hearth roll corrects (reduces) the off-center distance of strip in transverse direction, the change of offcenter distance of strip with respect to traveling distance processed is shown in Fig. 7.

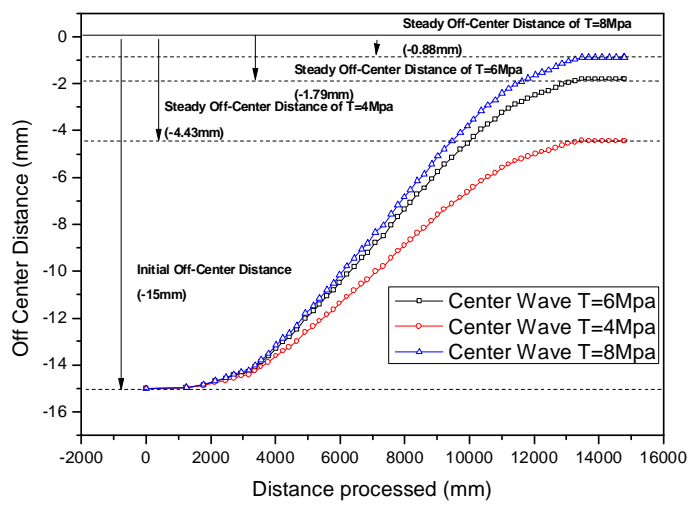

Fig. 7. The change of off-center distance of strip with different tension stress

For a given tapered hearth roll, keeping the values of strip width, thickness, wave width, wave height, wave length and initial off-center distance unchanged, the self-centering ability for $\mathrm{T}=8 \mathrm{Mpa}$ is greater than that for $\mathrm{T}=6 \mathrm{Mpa}$, however the self-centering ability for $\mathrm{T}=4 \mathrm{Mpa}$ is less than that for $\mathrm{T}=6 \mathrm{Mpa}$.the higher the tension is, the greater the self-centering ability is.

\section{Conclusions}

The paper investigated the influence of initial strip flatness defects on the self-centering ability of tapered hearth roll in continuous annealing. The concept of self-centering ability of tapered hearth roll was proposed in the first time, and the influence of both initial strip flatness and tension stress on it were studied. This paper provided a theoretical method on how to reduce strip off-centering distance and improve the stability by means of changing the initial flatness of strip and the tension stress in the furnace. The following conclusions are obtained:

1) The tapered hearth roll has the self-centering ability to move the strip with initial off-center distance toward the center of hearth roll .From the perspective of correcting the initial off-centering distance, the center wave is better than flat non-wave and flat non-wave is better than double edge wave .

2) The tapered hearth roll can not correct the initial off-centering distance $100 \%$, there is a steady state off-center distance remained that can be eliminated by means of devices like steering roll units or CPC units.

3 ) The self-centering ability of tapered hearth roll can be improved by increasing the tension stress in the furnace and the steady state off-centering distance can be decreased as well.

\section{References}

[1] J. Song, Development of continuous annealing technology for cold rolled steel sheet[J], Shanghai Metals, 21(4) (1999): 47-57.

[2] L.G. Gu, W.Z. Xu, Continuous annealing technology and continuous annealing line[J], Steel Rolling, (5) (2007): 13-17,30.

[3] J. Song, New development of annealing technology-continuous annealing[J], Steel Rolling, (3) (1993): 54-59.

[4] J.F. Zhu, Review on continuous annealing technology of hot dip galvanizing sheet for automobile[J], WISCO Technology, 45(1) (2007): 53-57. 
[5] T. Masui, Y. Kaseda, K. Isaka, Basic examination on strip wandering in processing plants[J], ISIJ International, 40(10) (2000): 1019-1023.

[6] T. Sasaki, T. Hira, H. Abe, F. Yanagishima, Y. Shimoyama, K. Tahara, Control of strip buckling and transverse-shifting in continuous annealing furnace[J], KAWASAKI Steel Technical Report, (9) (1984): 36-46.

[7] J. Ma, Research of correcting deviation system used in continuous annealing furnace[J], Sichuan Metallurgy, 34(2) (2012): 52-55.

[8] X. Liu. Control technology of steel strip deviation in continuous annealing line at Meigang[J], Baosteel Meishan, (6) (2013): 30-32.

[9] T. Sasaki,T. Hire, The controlling of steering in CAL furnace[J], Kawasaki Iron Report, (16) (1984): 37-45.

[10] Y.S. Yu, Z.X. He, J.N. Hu, Z.Y. Ouyang, Deviation and treatment of CAPL No.7 CPC at cold rolling plant[J], Baosteel Meishan, (6) (2011): 35-42.

[11] Q.Y. Kuang, Q.F. Xu, H.W. Xu, Analysis of strip off-tracking for ACL and improvement measures[J], Hydraulics Pneumatics \& Seals, (7) (2010): 12-15.

[12] X. Chang, L.M. Du, Effects of strip shape on running deviation of continuous annealing line[J], Journal of Iron and Steel Research, 24(S1) (2012): 60-63.

[13] X.L. Chen. Flatness control in new generation high-tech mills for wide strip rolling[J], Journal of University of Science and Technology Beijing, 19(S2) (1997): 5.

[14] X.L. Chen, Development trend of the new generation of high-tech thin strip cold rolling mills[J], Shanghai Metals, 17(4) (1995): 1-8.

[15] Z. Zhuang, The Analysis and Applications of Finite Element Method based on ABAQUS[M], first ed.,Tsinghua University Press, Beijing, 2009.

[16] Y.Q. Liu, J.X. Na, J. Wang, P. Hu, An effective element model for the numerical simulation of sheet metal forming[J], Journal of Jilin University of Technology, 27(1) (1997): 43-48.

[17] Y.P. Shi, Y.R. Zhou, Detailed examples of finite element analysis of ABAQUS[M], first ed., China Machine Press, Beijing, 2006. 